\title{
Transplant Registry Unified Management Program
}

National Cancer Institute

\section{Source}

National Cancer Institute. Transplant Registry Unified Management Program. NCI

Thesaurus. Code C158154.

A Japanese centralized, computer-based software suite developed to manage

hematopoietic stem cell transplant outcome data offline in transplant centers. The system emphasizes convenience to institutes, safety of patient information, quality of data management, and outcomes of transplantations. 